\title{
Silica-acac-supported palladium nanoparticles as an efficient and reusable heterogeneous catalyst in the Suzuki-Miyaura cross-coupling reaction in water
}

\author{
ABDOL REZA HAJIPOUR ${ }^{\mathrm{a}, \mathrm{b}, *}$, ZOHRE SHIRDASHTZADE $^{\mathrm{a}}$ and GHOBAD AZIZI ${ }^{\mathrm{a}}$ \\ aPharmaceutical Research Laboratory, Department of Chemistry, Isfahan University of Technology, \\ Isfahan 84156, IR Iran \\ ${ }^{\mathrm{b}}$ Department of Neuroscience, University of Wisconsin, Medical School, 1300 University Avenue, \\ Madison, WI 53706-1532, USA \\ e-mail: haji@cc.iut.ac.ir
}

MS received 9 August 2013; revised 21 October 2013; accepted 25 October 2013

\begin{abstract}
Supported Pd nanoparticles on acetyl acetone modified silica gel was prepared and its catalytic application in the Suzuki-Miyaura reaction of various aryl halides with phenylboronic acid was investigated. The reaction was carried out in water as solvent under green conditions in the presence of $\mathrm{NaHCO}_{3}$ as the base. The catalyst was characterized by a combination of powder XRD, XPS, TEM and SEM. The catalyst is not sensitive to air and moisture, so reactions were carried out without using inert atmosphere. The catalyst can be reused up to six times without significant loss of catalyst activity. The cumulative turnover number (TON) over six runs is 13525 .
\end{abstract}

Keywords. Supported palladium nanoparticles; Suzuki-Miyaura reaction; aryl halide; phenylboronic acid; heterogeneous catalyst.

\section{Introduction}

The Suzuki-Miyaura cross-coupling reaction is an important method for aryl-aryl bond formation, using aryl halides and phenylboronic acids. ${ }^{1-3}$ Significant studies that had been done in this area in the last decade are derived from numerous advantages of this reaction such as high stability of organoboranes towards air and moisture, low toxicity associated with boron compounds, mild and easy reaction conditions, use of aqueous inorganic bases and coupling of stearic hindered substrates. ${ }^{4-6}$ The Pd-catalysed Suzuki reactions are well-known as influential methods to construct $\mathrm{C}-\mathrm{C}$ bond in modern chemical transformations, ${ }^{7-9}$ and have found extensive use as much as of the utility of its products in the synthesis of natural products, pharmaceutical intermediates, agrochemical drug, advanced materials and liquid crystals. ${ }^{10-15}$

In spite of the fact that homogeneous palladium catalysts based on various Pd complexes along with some ligands ${ }^{16-18}$ or free of ligands, ${ }^{19,20}$ have been extensively used for Suzuki reaction, an outstanding disadvantage of these procedures is the difficulty in recovering and reusing the expensive catalyst. Overcoming this drawback using heterogeneous palladium catalysts

*For correspondence could be an attractive method since the heterogeneous catalysts can be easily separated from the reaction mixture. ${ }^{21-23}$ Thus, many studies have been concerned with the development of palladium catalysts, including immobilizing palladium complexes or nanoparticles on several supports. ${ }^{24-35}$ In the case of silica-supported palladium nanoparticles, several amorphous and porous supports have been used for Suzuki reaction. ${ }^{36-47}$

Recently, many studies have been devoted to the development of milder reaction conditions, and water has been currently used as a benign solvent in the Suzuki reaction. ${ }^{48-53}$ Water has obvious advantages as a solvent in organic synthesis, since it is the most abundant and inexpensive liquid on earth. Also, it is eco-friendly, nontoxic, and non-flammable solvent. ${ }^{54,55}$ Herein, we report a new heterogeneous and reusable catalyst for Suzuki-Miyaura cross-coupling reaction in water. The catalyst is not sensitive to air and displays high efficiency for biaryl synthesis. Moreover, this heterogeneous catalyst performed up to six runs without significant loss of activity.

\section{Experimental}

All starting materials were purchased from Merck and used without further purification. ${ }^{1} \mathrm{H}$ and ${ }^{13} \mathrm{C}$ NMR 
spectra were recorded on a Bruker 300 spectrometer using TMS as an internal standard in $\mathrm{CDCl}_{3}$ and FT-IR spectra were obtained as $\mathrm{KBr}$ pellets on a JASCO 680-PLUS spectrophotometer. The XPS spectra were obtained by X-ray photoelectron spectroscopy, Twin Anode X-Ray Soursce Systems (X-Ray 8025Bestes). Also we used GC (BEIFIN 3420 Gas Chromatograph equipped with a Varian CP SIL 5CB column $-30 \mathrm{~m}, 0.32 \mathrm{~mm}, 0.25 \mu \mathrm{m}$ ) for examination of reactions conversions. X-ray powder diffraction (XRD) were obtained by Philips X'Pert PRO over the $2 \theta$ range from $10-100^{\circ}$ at the rate of $2.58^{\circ} / \mathrm{min}$, using $\mathrm{Cu}-\mathrm{Ka}$ radiation $(\lambda=1.54060 \AA)$. Sizes of the synthesized particles were observed using transmission electron microscope (TEM, HITACHI H-700H) at an accelerating voltage of $150 \mathrm{kV}$. Samples were prepared by placing drops of diluted ethanol dispersed of catalyst particles on the surface of cooper grids and evaporation.

\subsection{General procedure for the Synthesis of the silica-acac-supported palladium nanoparticles}

Initially, to prepare activated silica, silica gel 60 (5 g) was soaked in concentrated $\mathrm{HCl}$ overnight and then resuspended in deionized water several times until the $\mathrm{pH}$ of the filtrate was higher than 6 . The acid-treated silica gel was dried at $150^{\circ} \mathrm{C}$ overnight and cooled in a desiccator. To prepare 3-iodopropyl trimethoxysilanesupported silica gel, activated silica gel ( $5 \mathrm{~g}$ ) was suspended in solution of 3-iodopropyl trimethoxysilane ( $5 \mathrm{mmol}$ ) in toluene. The suspension was refluxed for $24 \mathrm{~h}$. After cooling, the particles were collected by filtration and exhaustively washed with ethanol, and dried under reduced pressure to give iodoropropyl-silica gel. Iodoropropyl-silica gel re-suspended in $30 \mathrm{~mL}$ acetonitrile and $5 \mathrm{mmol}(0.50 \mathrm{~g})$ acetyl acetone and $5 \mathrm{mmol}(0.69 \mathrm{~g}) \mathrm{K}_{2} \mathrm{CO}_{3}$ were added and refluxed for
$24 \mathrm{~h}$. The solids were washed with water and soxhlated with ethanol for $5 \mathrm{~h}$ and dried under reduced pressure. Finally, the resulting solid was stirred with acetonitrile in the presence of $0.05 \mathrm{~g}$ of $\mathrm{Pd}(\mathrm{OAc})_{2}$ and after washing the solids by acetonitrile, the Pd(II)-acac-supported silica refluxed in acetonitrile to form a black solid. The black solid was washed with acetone and dried under vacuum at room temperature to obtain the desired catalyst. The Pd-amount was $0.04 \mathrm{mmol} / \mathrm{g}(4.26 \mathrm{mg} / \mathrm{g})$ determined using AAS.

\subsection{General procedure for the Suzuki reaction of aryl halides with phenylboronic acid}

A mixture of the appropriate aryl halide $(1 \mathrm{mmol})$, phenylboronic acid $(1.2 \mathrm{mmol}), \mathrm{SiO}_{2}$-acac-PdNPs catalyst (10 mg, $0.0004 \mathrm{mmol}, 0.04 \mathrm{~mol} \%), \mathrm{NaHCO}_{3}$ ( $2 \mathrm{mmol}$ ) was added to water $(3 \mathrm{~mL})$ in a roundbottom flask equipped with condenser and refluxed under heating conditions in reflux temperature. The mixture was stirred continuously during the reaction. After the reaction was completed (monitored by TLC, 90/10 hexane/EtOAc), the mixture was cooled to room temperature and the catalyst was separated by filtration, washed thrice with water and acetone and allowed to dry at room temperature for $30 \mathrm{~min}$ under vacuum for the next run. The reaction mixture was poured into a separating funnel and water $(20 \mathrm{~mL})$ and $\mathrm{n}$-hexane $(10 \mathrm{~mL})$ were added and extracted for thrice. The combined organic phases were dried over $\mathrm{CaCl}_{2}$, filtered, and the solvent was evaporated. The residue was the products which were various biaryls. In some cases, the residue was purified by column chromatography (silica gel 60, EtOAc: n-hexane 10:90). All the products were known and characterized by melting point, IR and ${ }^{1} \mathrm{H}$ NMR spectroscopy and were compared with authentic samples. The data were found to be identical to those reported in the literature.

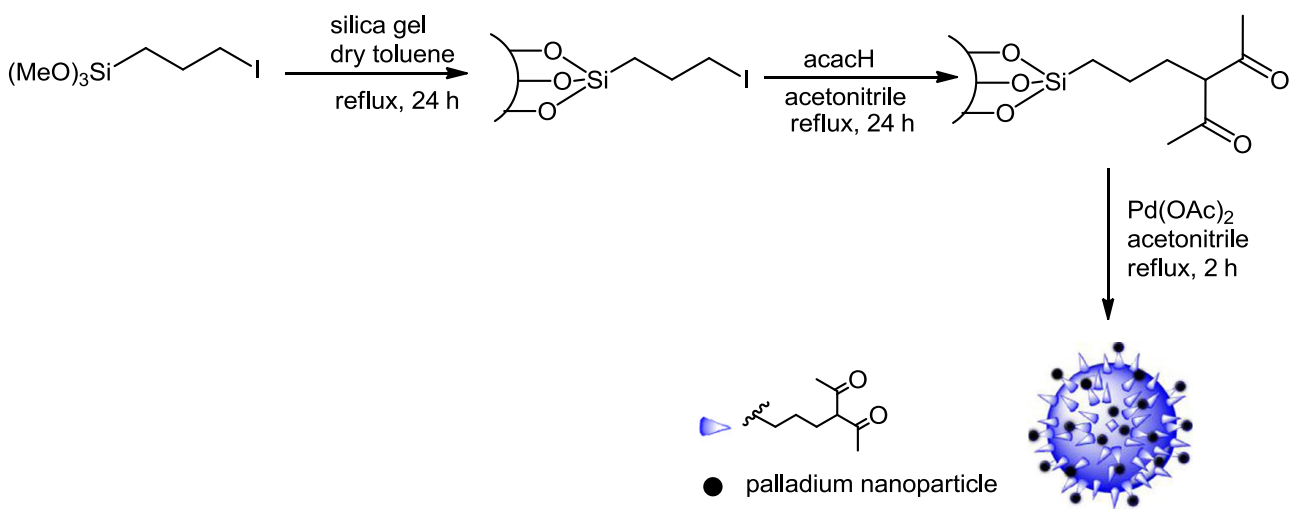

Scheme 1. Synthetic route for preparation of the catalyst. 


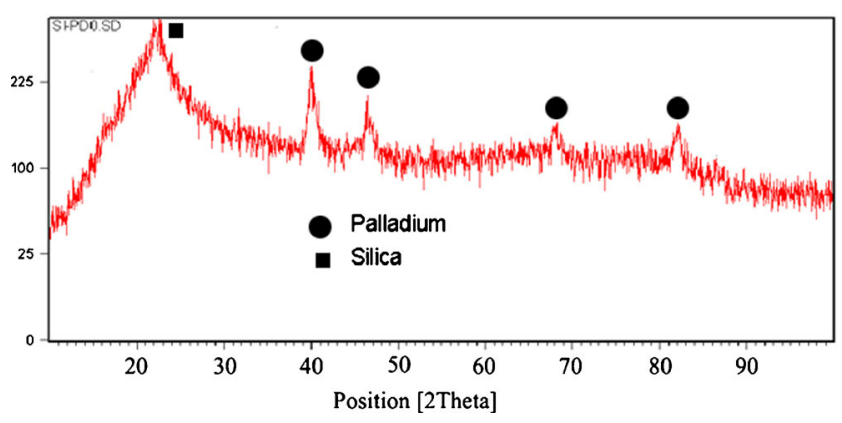

Figure 1. Powder X-ray diffraction (XRD) pattern of palladium nanoparticles supported on silica.

\section{Results and discussion}

Synthetic route for preparation of the catalyst is shown in scheme 1. The catalyst is represented as $\mathrm{SiO}_{2}$-acacPdNPs. In this study, we utilize acetonitrile as reducing agent for reduction of palladium(II) to palladium(0) nanoparticles. As Susharina and co-workers mentioned earlier on the oxidation of acetonitrile by using platinum catalysts, oxidation of acetonitrile in the presence of oxygen leads to formation of $\mathrm{CO}_{2}, \mathrm{H}_{2} \mathrm{O}, \mathrm{N}_{2}$ and $\mathrm{NO}_{x}$ at high temperatures. ${ }^{56}$ As we did not observe any changes in GC chromatograms (FID detector) of acetonitrile (HPLC grade) after and before reduction of palladium, we believe that the formation of these products may be probable during reduction of palladium with acetonitrile.

Characterization of heterogeneous catalyst was studied using XRD, XPS, SEM and TEM analysis. Results indicate that palladium content of the catalyst is $0.04 \mathrm{mmol} / \mathrm{g}(4.26 \mathrm{mg} / \mathrm{g})$. As shown in figure 1, XRD pattern of catalyst that matched well with that of it (Reference code: 00-005-0681) shows the presence of metallic palladium phases $(2$ theta $=40.1,46.5,68.0$ and 86.0) and amorphous silica $(2$ theta $=22.0)$ and is consistent with the metallic palladium $(0)$ data in the literature. ${ }^{57}$ Also, we can see that no characteristic peaks of impurities were observed. Results from XRD indicate that palladium nanoparticles have been successfully immobilized on the surface of silica-acac.

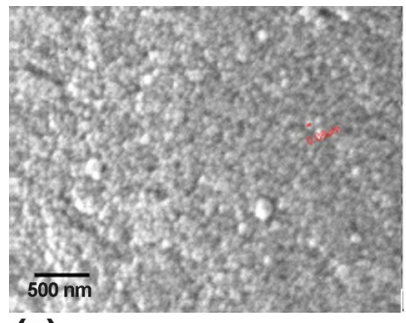

(a)

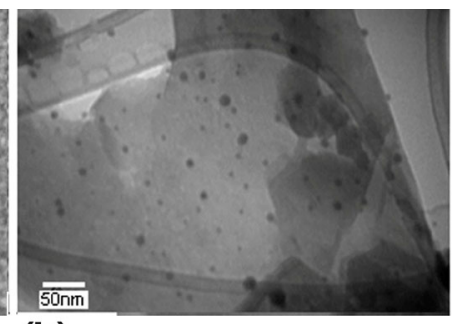

(b)
Figure 2. (a) SEM and (b) TEM images of the palladium nanoparticles supported on the surface of silica gel.
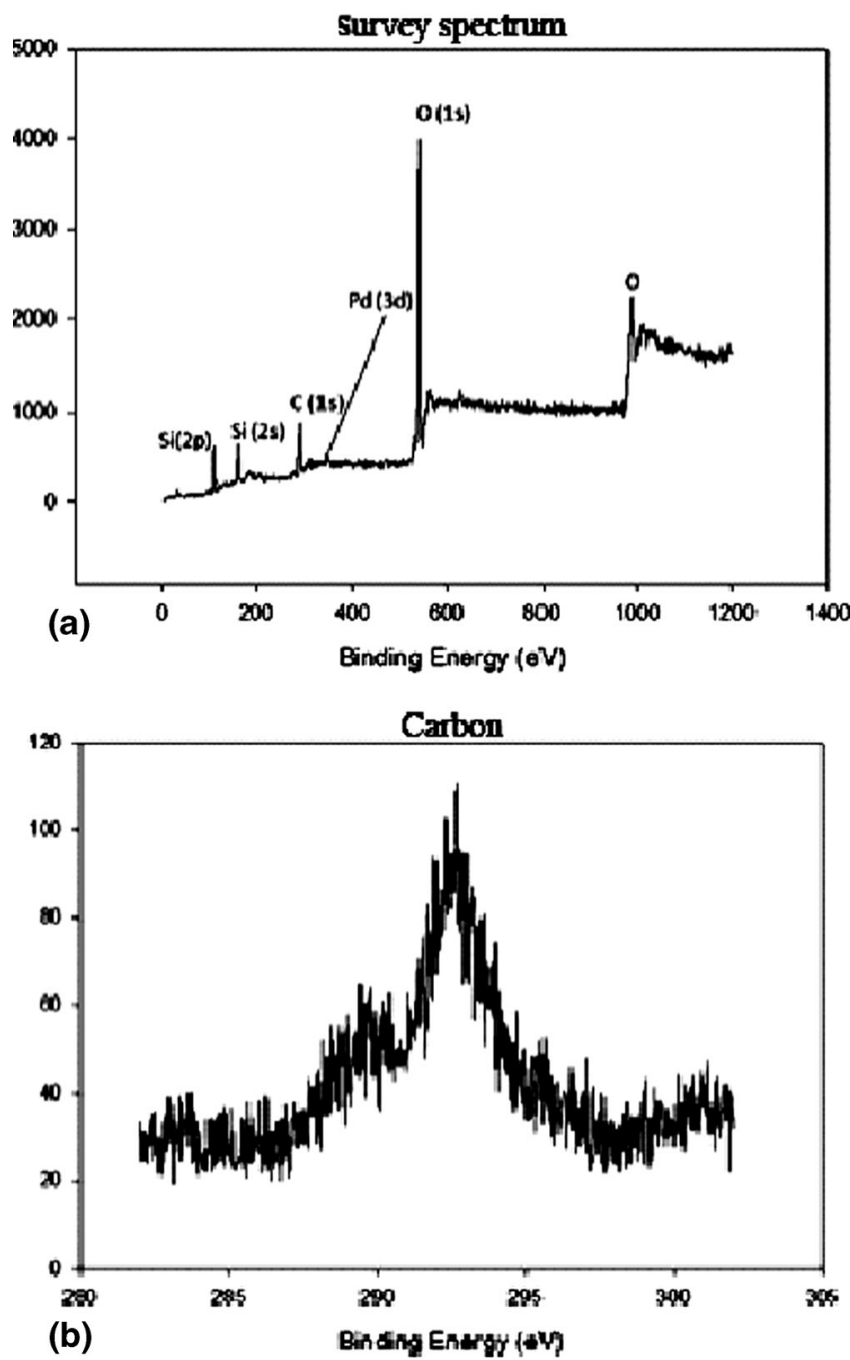

palladium

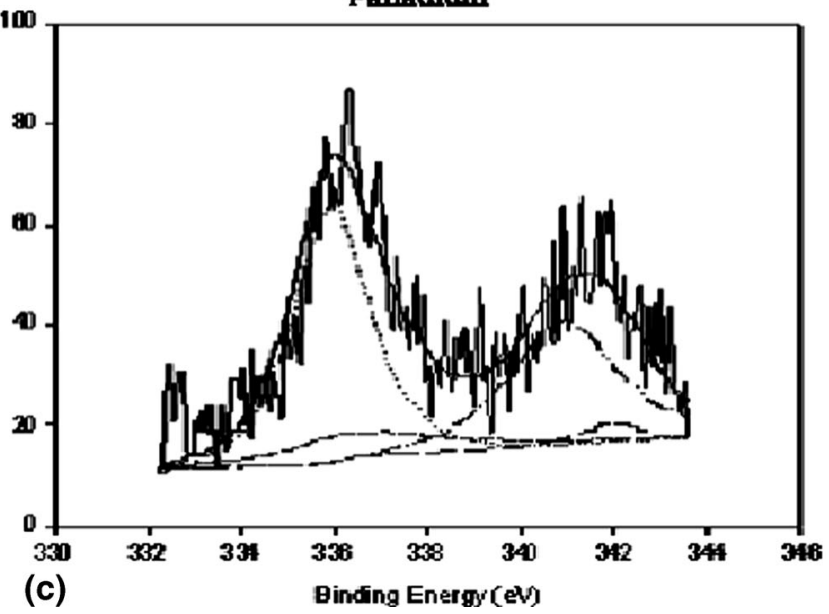

Figure 3. XPS spectra of the catalyst: (a) survey spectrum, (b) $\mathrm{C}_{1 s}$, and (c) $\mathrm{Pd}_{3 \mathrm{~d}}$.

The SEM image (figure 2a) in accordance with broad peak of silica in XRD spectra, shows that the catalyst was almost amorphous. Dark spots in the TEM image (figure $2 b$ ) indicate the presence of palladium nanoparticles in the range of 6-12 $\mathrm{nm}$. 
Table 1. Optimization of base and solvent for the Suzuki reaction of 4bromoacetophenone with phenylboronic acid. ${ }^{\mathrm{a}}$

\begin{tabular}{|c|c|c|c|}
\hline Entry & Base & Solvent & Conversion $(\%)^{\mathrm{b}}$ \\
\hline 1 & $\mathrm{NaHCO}_{3}$ & $\mathrm{EtOH}$ & 85 \\
\hline 2 & $\mathrm{NaHCO}_{3}$ & $\mathrm{MeOH}$ & 87 \\
\hline 3 & $\mathrm{NaHCO}_{3}$ & $\mathrm{H}_{2} \mathrm{O}$ & 90 \\
\hline 4 & $\mathrm{NaHCO}_{3}$ & DMF & 60 \\
\hline 5 & $\mathrm{NaHCO}_{3}$ & NMP & 25 \\
\hline 6 & $\mathrm{NaHCO}_{3}$ & $\mathrm{CH}_{3} \mathrm{CN}$ & 50 \\
\hline 7 & $\mathrm{NaHCO}_{3}$ & Dioxane & 10 \\
\hline 8 & $\mathrm{Na}_{2} \mathrm{CO}_{3}$ & $\mathrm{H}_{2} \mathrm{O}$ & 40 \\
\hline 9 & $\mathrm{NaOH}$ & $\mathrm{H}_{2} \mathrm{O}$ & 0 \\
\hline 10 & $\mathrm{Et}_{3} \mathrm{~N}$ & $\mathrm{H}_{2} \mathrm{O}$ & 0 \\
\hline 11 & $\mathrm{Na}(\mathrm{OAC})$ & $\mathrm{H}_{2} \mathrm{O}$ & 20 \\
\hline 12 & $\mathrm{~K}_{2} \mathrm{CO}_{3}$ & $\mathrm{H}_{2} \mathrm{O}$ & 30 \\
\hline
\end{tabular}

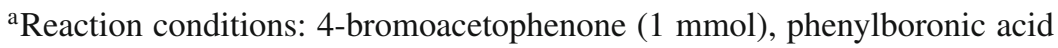
(1.2 mmol), $20 \mathrm{mg}$ catalyst, various bases and solvents

${ }^{\mathrm{b}} \mathrm{GC}$ conversion

The catalyst was also characterized by XPS analysis, and the results are shown in figure 3. Figure 3a shows the survey spectrum of catalyst and it is obvious that $\mathrm{C}$ and $\mathrm{Pd}$ were present in the catalyst. Figure $3 \mathrm{~b}$ illustrates the $\mathrm{C}_{1 s}$ spectrum, in which the peak centred at $293 \mathrm{eV}$ is attributed to $\mathrm{C}$ species, which originated from the acac and propyl groups, suggesting that organic moieties existed in the surface of the catalyst. From figure $2 \mathrm{c}$, it can be seen that the $\mathrm{Pd}_{3 \mathrm{~d}}$ spectrum could be resolved into two spins - orbit pairs with $3 \mathrm{~d} 5 / 2$ binding energies of 336 and $337 \mathrm{eV}$. Peak binding energies of $336 \mathrm{eV}\left(\mathrm{Pd}_{3 \mathrm{~d} 5 / 2}\right)$ and $341.0 \mathrm{eV}\left(\mathrm{Pd}_{3 \mathrm{~d} 3 / 2}\right)$ correspond to fully reduced palladium, while the peaks at 337 and $342.1 \mathrm{eV}$ are assigned to the palladium(II) species, which may result from incomplete reduction of palladium. It can be seen from the XPS spectrum that most of $\mathrm{Pd}^{2+}$ was reduced to $\mathrm{Pd}^{0}$ because the area of the peak of $\mathrm{Pd}^{2+}$ ion was relatively small.

Table 2. Optimization of base and catalyst concentration for the Suzuki reaction of 4-bromoacetophenone with phenylboronic. ${ }^{\mathrm{a}}$<smiles>CC(=O)c1ccc(Br)cc1</smiles>

\begin{tabular}{lccc}
\hline Entry & Cat. $(\mathrm{mg})$ & Base $(\mathrm{mmol})$ & Conversion $(\%)^{\mathrm{b}}$ \\
\hline 1 & 5 & 2 & 80 \\
2 & 10 & 2 & $>99$ \\
3 & 20 & 2 & $>99$ \\
4 & 40 & 2 & 100 \\
5 & 10 & 1 & 65 \\
6 & 10 & 2 & 99 \\
7 & 10 & 4 & 99 \\
\hline
\end{tabular}

a Reaction conditions: 4-bromoacetophenone ( $1 \mathrm{mmol})$, phenylboronic acid $(1.2 \mathrm{mmol})$, water $(1.5 \mathrm{ml})$, reflux

${ }^{\mathrm{b}} \mathrm{GC}$ conversion 
In order to optimize the reaction conditions, the reaction in various solvents in the presence of different bases was tried. Initially, the Suzuki reaction conditions were optimized for the reaction of 4-bromoacetophenone and phenylboronic acid in the presence of various solvents and bases using $20 \mathrm{mg}$ of catalyst. According to data present in table 1, water was the most efficient solvent and $\mathrm{NaHCO}_{3}$ was chosen as the best base for this reaction (table 1, entry 3 ).

The concentration of base and catalyst was also optimized by employing various amounts of base and catalyst for the reaction of 4-bromoacetophenone and phenylbronic acid, using $10 \mathrm{mg}(0.0004 \mathrm{mmol}$, $0.04 \mathrm{~mol} \% \mathrm{Pd}$ ) of catalyst and 2 equivalents of base gave the best results (table 2, entry 2). The catalyst was completely stable and thus the reactions could be carried out without using inert atmosphere. These reaction conditions were applied in the Suzuki reaction of different types of aryl halides with phenylboronic acids under reflux conditions (table 3 ).

As demonstrated in table 3, the catalyst can be used for cross-coupling reaction of aryl iodides, bromides and even less reactive aryl chlorides under heating conditions in reflux temperature, and they were transformed to the corresponding coupled products in good to excellent yields in short reaction times. However, aryl chlorides were reacted more slowly in comparison to the iodides and bromides derivatives. Reactions were performed with both electron-donating and electronwithdrawing groups and the results are demonstrated in table 3 , the reaction did not show any significant sensitivity to electronic effects. Also, selectivity of the catalyst was examined by using ortho-, meta- and para- bromochlorobenzene (table 3, entries 4-6); in each case, only $\mathrm{Br}$ as the better leaving group was substituted and "Cl did not enter the reactions;" this means that the reaction acts chemo-selectively and in comparison to $\mathrm{Cl}, \mathrm{Br}$ is a better leaving group.

In addition, we found that most hindered aryl halides usually produce corresponding biaryls in longer reaction times and lower yields. To show the effect of stearic hindrance in the Suzuki coupling reaction and applicability of the catalyst for stearically hindered aryl halides, we tried the coupling of 1-bromo-2nitrobenzene, 2-bromo toluene and 2, 6-dimethyl bromobenzene and found that the reaction of these compounds took place in longer times (entries 17, 22 and 23).

Recycling of the catalyst was examined for the coupling reaction of iodobenzene with phenylboronic acid under optimized reaction conditions (iodobenzene $(0.25 \mathrm{mmol})$, phenylboronic acid $(0.3 \mathrm{mmol}), \mathrm{NaHCO}_{3}$ $(0.5 \mathrm{mmol})$, catalyst $(0.04 \mathrm{~mol} \%)$ and water $3 \mathrm{ml})$ in reflux temperature. After the first run of the catalyst, the reaction mixture was allowed to cool to room temperature and the catalyst was separated by filtration, washed with $\mathrm{H}_{2} \mathrm{O}$ and acetone (thrice) and allowed to dry at room temperature for $30 \mathrm{~min}$ under vacuum. The recycled catalyst was reused under the same reaction conditions. The catalyst could be recycled four times

Table 3. Suzuki reaction of aryl halides with phenylboronic acid in water at reflux temperature ${ }^{\mathrm{a}}$.

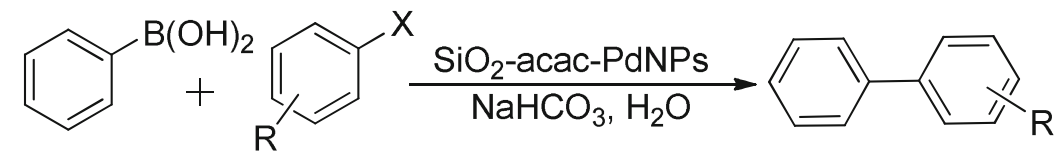

\begin{tabular}{lllll}
\hline Entry & ArX & Product & Time (min) & Yield (\%) \\
\hline
\end{tabular}

\begin{tabular}{|c|c|c|c|}
\hline & $\mathrm{TON}^{\mathrm{b}}$ & $\mathrm{TOF} / \mathrm{h}^{\mathrm{c}}$ & \\
\hline Run 1 & 2350 & 392 & 6 \\
\hline Run 2 & 2375 & 396 & 6 \\
\hline Run 3 & 2300 & 383 & 6 \\
\hline Run 4 & 2250 & 375 & 6 \\
\hline Run 5 & 2200 & 314 & 7 \\
\hline Run 6 & 2050 & 292 & 7 \\
\hline Total TON & 13525 & & \\
\hline
\end{tabular}


Table 3. (continued)

\begin{tabular}{|c|c|c|c|c|}
\hline Entry & ArX & Product & Time (min) & Yield (\%) \\
\hline 2 & & & 8 & 94 \\
\hline 3 & & & 20 & 84 \\
\hline 4 & & & 6 & 90 \\
\hline 5 & & & 7 & 91 \\
\hline 6 & & & 8 & 85 \\
\hline 7 & & & 50 & 92 \\
\hline 8 & & & 95 & 87 \\
\hline 9 & & & 125 & 58 \\
\hline 10 & & & 20 & 91 \\
\hline 11 & & & 17 & 89 \\
\hline
\end{tabular}


Table 3. (continued)

\begin{tabular}{|c|c|c|c|c|}
\hline Entry & $\operatorname{ArX}$ & Product & Time (min) & Yield (\%) \\
\hline 12 & & & 19 & 90 \\
\hline 13 & & & 13 & 91 \\
\hline 14 & & & 10 & 92 \\
\hline 15 & & & 45 & 94 \\
\hline 16 & & & 45 & 91 \\
\hline 17 & & & $6 \mathrm{~h}$ & 80 \\
\hline 18 & & & $4 \mathrm{~h}$ & 93 \\
\hline 19 & & & 17 & 88 \\
\hline 20 & & & 12 & 86 \\
\hline 21 & & & 15 & 87 \\
\hline
\end{tabular}


Table 3. (continued)

Entry Time (min) Yield (\%)

\footnotetext{
a Reaction conditions: aryl halide $(1 \mathrm{mmol})$, phenylboronic acid $(1.2 \mathrm{mmol})$, base $(2 \mathrm{mmol}), 10 \mathrm{mg}$ catalyst and $3 \mathrm{ml}$ water as solvent

${ }^{\mathrm{b}}$ TON (turnover number) $=$ product $(\mathrm{mmol}) /$ catalyst $(\mathrm{mmol})$

${ }^{\mathrm{c}} \mathrm{TOF}$ (turnover frequency) $=\mathrm{TON} /$ reaction time $(\mathrm{h})$
}

with essentially no loss in activity, even after recycling six times, yield of product could still be obtained at $82 \%$ (table 3 , entry 1 ). The cumulative turnover number (TON) over six runs was 13525 . We performed the FT-IR analysis for studying the fate of acac in the catalyst after six catalytic runs. The FT-IR spectra clearly showed the absorption bands of acac and confirmed that acac is still present on the catalyst surface.

\section{Conclusion}

In summary, we found that palladium nanoparticles could be stably immobilized onto the surface of ligandmodified silica gel, and thus could act as highly active and reusable catalyst for promoting the SuzukiMiyaura cross-coupling reaction of various aryl halides with phenylboronic acids to produce the corresponding products in excellent yields with high chemo-selectivity and acceptable reaction times.

\section{Acknowledgements}

We thank the Isfahan University of Technology (IUT), IR Iran for funding support. Further, financial support from the Center of Excellence in Sensor and Green Chemistry Research (IUT) is also thanked.

\section{References}

1. Das P, Sharma D, Shil A K and Kumar A 2011 Tetrahedron Lett. 521176

2. Miyaura N and Suzuki A 1995 Chem. Rev. 952457

3. Ikegami S and Hamamoto H 2009 Chem. Rev. 109583

4. Amoroso F, Colussi S, zotto A D, Llorca J and Trovarelli A 2011 Catal. Commun. 12563

5. John A, Shaikh M M and Ghosh P 2010 Inorg. Chim. Acta $\mathbf{3 6 3} 3113$
6. Alonso F, Beletskaya I P and Yus M 2008 Tetrahedron 643047

7. Wang J, Song G and Peng Y 2011 Tetrahedron Lett. 52 1477

8. Zarei A, Khazdooz L, Hajipour A R, Rafiee F, Azizi G and Abrishami F 2012 Tetrahedron Lett. 53406

9. Kitamura Y, Sakurai A, Udzu T, Maegawa T, Monguchi Y and Sajik H 2007 Tetrahedron 6310596

10. Wang J, Seefeld M A and Luengo J 2011 Tetrahedron Lett. 526346

11. Hargreaves S L, Pilkington B L, Russell S E and Worthington P A 2000 Tetrahedron Lett. 411653

12. Phakhodee W, Toyoda M, Chou C M, Khunnawutmanotham N and Isobe M 2011 Tetrahedron 671150

13. Afonso A, Feliu L and Planas M 2011 Tetrahedron 67 2238

14. Borhade S R and Waghmode S B 2011 Beilstein J. Org. Chem. 7310

15. Yang H, Han X, Li G and Wang Y 2009 Green Chem. 111184

16. Fleckenstein C A and Plenio H 2010 Chem. Soc. Rev. 39 694

17. Marion N and Nolan S P 2008 Acc. Chem. Res. 411440

18. Amatore C and Jutand A 1998 Coord. Chem. Rev. 178 511

19. Molander G A and Biolatto B 2003 J. Organomet. Chem. 684302

20. Kabalka G W, Namboodiri V and Wang L 2001 Chem. Commun. 775

21. Molander G A and Biolatto B 2002 Org. Lett. 41867

22. Yang J, Li P and Wang L 2011 Synthesis 1295

23. Chen W, Li P and Wang L 2011 Tetrahedron 67318

24. Senapati K K, Roy S, Borgohain C and Phukan P 2012 J. Mol. Catal. A: Chem. 352128

25. Zhao H, Peng J, Xiao R and Cai M 2011 J. Mol. Catal. A: Chem. 33756

26. Li L, Shi J L and Yan J N 2004 Chem. Commun. 171990

27. Artok L and Bulut H 2004 Tetrahedron Lett. 453881

28. Corma A, Iborra S, Xamena F X L, Monton R, Calvino J J and Prestipino C 2010 J. Phys. Chem. C114 8828 
29. Tao R, Miao S, Liu Z, Xie Y, Han B, An G and Ding K 2009 Green Chem. 1196

30. Costa N J S, Kiyohara P K, Monteiro A L, Coppel Y, Philippot K and Rossi L M 2010 J. Catal. 276382

31. Zhang F, Jin J, Zhong X, Li S, Niu J, Li R and Ma J 2011 Green Chem. 131238

32. Cirtiu C M, Dunlop-Briere A F and Moores A 2011 Green Chem. 13288

33. Senapati K K, Roy S, Borgohain C and Phukan P 2012 J. Mol. Catal. A: Chem. 352128

34. Polshettiwar V and Varma R S 2009 Org. Biomol. Chem. 737

35. Gruber-Woelfler H, Radaschitz P F, Feenstra P W, Haas W and Khinast J G 2012 J. Catal. 28630

36. Das D D and Sayari A 2007 J. Catal. 24660

37. Gude K and Narayanan R 2011 J. Phys. Chem. C115 12716

38. Fihri A, Cha D, Bouhrara M, Almana $\mathrm{N}$ and Polshettiwar V 2012 ChemSusChem 585

39. MacQuarrie S, Nohair B, Horton J H, Kaliaguine S and Crudden C M 2010 J. Phys. Chem. C114 57

40. Wang L and Cai C 2009 J. Mol. Catal. A: Chem. 30697

41. Yang H, Han X, Lia G and Wang Y 2009 Green Chem. 111184

42. Karimi B, Elhamifar D, Clark J H and Hunt A J 2010 Chem. Eur. J. 168047

43. Ungureanu S, Deleuze H, Babot O, Achard M-F, Sanchez C, Popa M I and Backov R 2010 Appl. Catal. A: General 39051
44. Iranpoor N, Firouzabadi H, Motevalli S and Talebi M 2012 J. Organomet. Chem. 708-709 118

45. Iranpoor N, Firouzabadi H, Safavi A, Motevalli S and Doroodmand M M 2012 Appl. Organometal. Chem. 26 417

46. Budroni G, Corma A, García H and Primo A 2007 J. Catal. 251345

47. Xu Y, Zhang Z, Zheng J, Du Q and Li Y 2013 Appl. Organometal. Chem. 2713

48. Polshettiwar V, Hesemann P and Moreau J E 2007 Tetrahedron 636784

49. Ohtaka A, Tamaki Y, Igawa Y, Egami E, Shimomura O and Nomura R 2010 Tetrahedron 665642

50. Dupuis C, Adiey K, Charruault L, Michelet V, Savignac M and Genet J P 2001 Tetrahedron Lett. 426523

51. Leadbeater N E 2005 Chem. Commun. 2881

52. Moore L R and Shaughnessy K H 2004 Org. Lett. 6225

53. Arcadi A, Cerichelli G, Chiarini M, Correa M and Zorzan D 2003 Eur. J. Org. Chem. 104080

54. Lamblin M, Nassar-Hardy L, Hierso J C, Fouquet E and Felpin F X 2010 Adv. Synth. Catal. 35233

55. Pawar S S, Uppalla L S, Shingare M S and Thore S N 2008 Tetrahedron Lett. 495858

56. Susharina T L, Kerzhentsev M A, Pod'yacheva O Yu and Ismagilov Z R 1986 React. Kinet. Catal. Lett. 3127

57. Martinez S, Vallribera A, Cotet C L, Popovici M, Martin L, Roig A, Moreno-Manas M and Molins E 2005 New J. Chem. 291342 